GRASAS Y ACEITES 68 (4)

October-December 2017, e216

ISSN-L: 0017-3495

doi: http://dx.doi.org/10.3989/gya.0554171

\title{
Walnut and almond oil screw-press extraction at industrial scale: Effects of process parameters on oil yield and quality
}

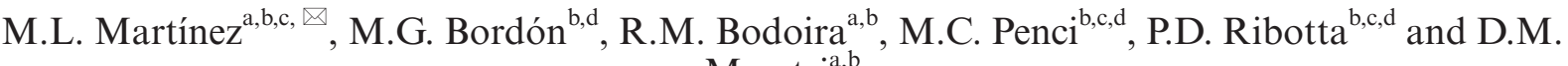 \\ Maestri ${ }^{\mathrm{a}, \mathrm{b}}$ \\ ${ }^{a}$ Instituto Multidisciplinario de Biología Vegetal (IMBIV-CONICET). \\ ${ }^{b}$ Instituto de Ciencia y Tecnología de los Alimentos (ICTA). Facultad de Ciencias Exactas, Físicas y Naturales (FCEFyN). \\ ${ }^{c}$ Departamento de Química Industrial y Aplicada. Facultad de Ciencias Exactas. Físicas y Naturales (FCEFyN). \\ ${ }^{\mathrm{d}}$ Instituto de Ciencia y Tecnología de los Alimentos Córdoba (ICYTAC-CONICET). \\ a,b,c,d Universidad Nacional de Córdoba. Argentina. \\ Corresponding author: marcelamartinez78@hotmail.com
}

Submitted: 18 May 2017; Accepted: 11 July 2017

\begin{abstract}
SUMMARY: Walnut and almond kernels are highly nutritious mainly due to their high oil contents. In this study, $3^{2}$ factorial experimental designs were used to optimize processes for oil extraction by screw-pressing at industrial scale. Experimental designs included seed moisture content (SMC), and restriction die (RD) as the main processing parameters. Theoretical models were scanned against experimental data in order to optimize oil extraction conditions. The response variables analyzed were oil yield (OY), fine solid content (FC) in oil, and oil quality parameters. Fitted models for OY indicated maximum predicted values similar to the highest experimental values. Walnut oil extractions showed a maximum OY $(84.5 \pm 2.3 \%)$ at $7.21 \% \mathrm{SMC}$, and $10 \mathrm{~mm}$ RD. For almond kernels, maximum OY $(71.9 \pm 3.5 \%)$ was obtained at $9.42 \% \mathrm{SMC}$, and $12 \mathrm{~mm} \mathrm{RD}$. Chemical quality parameters from both oils were in the ranges stated in Codex (FAO/WHO) standards for virgin (non-refined) oils.
\end{abstract}

KEYWORDS: Almond oil; Chemical quality parameters; Oil recovery; Screw-press extraction; Walnut oil

RESUMEN: Extracción de aceite de nuez y almendra a escala industrial: efecto de parámetros del proceso sobre el rendimiento y la calidad del aceite. La nuez y almendra son frutos sumamente nutritivos debido a su alto contenido de aceite. Mediante un diseño experimental de tipo factorial $3^{2}$ se optimizó el proceso de extracción de estos aceites con prensa de tornillo a escala industrial. Las variables de proceso analizadas fueron el contenido de humedad de la semilla (CHS) y el diámetro de reducción (DR). Los modelos ajustados para rendimiento de aceite (RA) indicaron valores máximos predichos similares a los valores experimentales. Las extracciones de aceite de nuez mostraron un RA máximo $(84,5 \pm 2,3 \%)$ a 7,21\% CHS, y $10 \mathrm{~mm}$ DR. Para almendra, se obtuvo un máximo de RA $(71,9 \pm 3,5 \%)$ con $9,42 \%$ de CHS y $12 \mathrm{~mm}$ de DR. Los parámetros de calidad química de ambos aceites se encontraban en los rangos establecidos en las normas del Codex (FAO / OMS) para aceites vírgenes (no refinados).

PALABRAS CLAVE: Aceite de almendra; Aceite de nuez; Extracción por prensado; Parámetros de calidad química; Rendimiento de aceite

ORCID ID: Martínez ML http://orcid.org/0000-0002-6236-7903, Bordón MG http://orcid.org/0000-0003-0249-7535, Bodoira RM http://orcid.org/0000-0002-3808-7899, Penci MC http://orcid.org/0000-0003-4953-4356, Ribotta PD http://orcid.org/0000-0001-7883-8856, Maestri DM https://orcid.org/0000-0002-1104-9323

Citation/Cómo citar este artículo: Martínez ML, Bordón MG, Bodoira RM, Penci MC, Ribotta PD, Maestri DM 2107. Walnut and almond oil screw-press extraction at industrial scale: Effects of process parameters on oil yield and quality. Grasas Aceites 68 (4), e216. http://dx.doi.org/10.3989/gya.0554171

Copyright: (C2017 CSIC. This is an open-access article distributed under the terms of the Creative Commons Attribution (CC-by) Spain 3.0 License. 


\section{INTRODUCTION}

Walnuts (Juglans regia L.) and almonds (Prunus dulcis (Miller) D.A. Webb P. amygdalus Batsch) are crops of increasing interest for the food industry. Worldwide productions are about 3.400 .000 and 1.934.817 tn, respectively (FAO, 2015). The kernel is the edible part of these nuts. They are considered important snacks and confectionary foods, with important nutritional value arising primarily from their high lipid content.

Both walnut and almond kernels contain high levels of oil (52-70 and $48-67 \%$, respectively) (Martínez et al., 2008; Martínez et al., 2013; Martínez and Maestri, 2015). Walnut oil (WO) is mainly composed of polyunsaturated fatty acid (linoleic and linolenic acids together represent $65-75 \%$ of the total fatty acid (FA) content). In contrast, almond oil (AO) mainly contains oleic acid (a monounsaturated fatty acid, $50-70 \%$ of the total FA content). Detailed compositions of these nut oils, including genetic and geographical variations, can be obtained from studies by Kodad et al., 2008, Martínez et al., 2010, Maestri et al., 2015 and Martínez and Maestri, 2015, among others.

Walnut and almond oils are produced at small scale mainly in France, Spain, Argentina, and the USA. They are used as salad dressing and in cosmetic industries as skin cream components. Traditionally, these oils have been extracted by pressing, either using a screw press or a hydraulic press. Generally, oil extraction by screw-pressing has some advantageous over hydraulic-pressing including higher oil yields and the possibility of continuous or semi-continuous processes. This latter feature makes the extraction a promising procedure for its application at industrial scale. They also provide a simple and reliable technology for processing small batches of oilseeds, yielding oils with good chemical quality, which is highly dependent on the process conditions (Wiesenborn et al., 2001, Singh et al., 2002; Zengh, 2003). Furthermore, Owolarafe et al. (2002) compared both types of mechanical presses with regards to yield, chemical quality and costs for palm oil extraction. No differences in chemical quality were observed and the screw-press type was more efficient and economical.

It is important to note, however, that screwpressing performance strongly depends on the raw material conditioning methods. These consist of a number of unit operations such as cracking, cooking, flaking, drying or moistening (Wiesenborn et al., 2001; Martínez et al., 2008; Savoire et al., 2013; Martínez and Maestri, 2015; Martínez et al., 2017). Seed moisture content appears to be a key process variable, as reported in several research projects with various oilseeds (Singh and Bargale, 1990; 2000; Hamm and Hamilton, 2000; Wiesenborn et al., 2001; Singh et al., 2002; Martínez et al., 2008; 2012; 2013; 2017).
Using screw-pressing at pilot plant scale, the highest oil recoveries from both walnut and almond kernels were obtained at similar moisture contents (Martínez et al., 2008; 2013). In each case, the oil extraction performance was also dependent on the pressing temperature and other processing conditions. On the basis of these studies, the present work was aimed to scale-up the oil extraction processes at industrial scale. Theoretical models were run against experimental data in order to optimize extraction conditions that gave both higher oil recovery and better oil quality.

\section{MATERIALS AND METHODS}

\subsection{Seed material}

Walnut (Juglans regia L. Var. Criolla) and almond (Prunus dulcis Miller. Var. Guara) fruits were obtained from commercial plantations in the Salta and Mendoza provinces (Argentina), respectively. After cleaning, the fruits were shelled and the kernels were recovered, packed in polypropylene bags, and stored at $5{ }^{\circ} \mathrm{C}$ until further use. Walnut kernels contained $69.2 \%$ oil (Dry Basis: DB) and 3.24\% seed moisture content (SMC) (Wet Basis: WB); almond kernels had $53.0 \%$ oil (DB) and $4.50 \%$ SMC (WB).

\subsection{Screw-press extraction}

The kernels were milled and sieved through an automatic sieve (EJR 2000 Zonytest ${ }^{\circledR}$ ), and particles between $1.43-4.76 \mathrm{~mm}$ were selected. These sifted materials were conditioned by water-sprinkling according to Singh and Bargale (2000) to achieve SMC of 5.50, 7.75, 8.00 and 10.0\% (WB) for walnut kernels, and 9.00, 10.0 and $11.0 \%$ (WB), for almond kernels. To adjust the SMC of walnut kernel particles to a $3.00 \%$ (WB) level, samples were kept in a vacuum oven at $25^{\circ} \mathrm{C}$.

Oil extraction was carried out in a single step with a Komet screw press (Model DD85G, IBG Monforts, Mönchengladbach, Germany). The effective and total length and the internal diameter of the press barrel were $6.7 \mathrm{~cm}, 14.7 \mathrm{~cm}$ and $5.60 \mathrm{~cm}$, respectively. The length and diameter of the screw were $19.5 \mathrm{~cm}$ and $5.3 \mathrm{~cm}$, respectively. All extractions were performed at $35-40^{\circ} \mathrm{C}$, at a screw speed of $20 \mathrm{rpm}$. The amount of sample pressed in each run was $1.50 \mathrm{~kg}$. The screw press was first run with heating for $15 \mathrm{~min}$ without seed material to raise the screw-press barrel temperature to the desired temperature. Then, in order to reach the steady-state operation, $3.00 \mathrm{~kg}$ of material was allowed to pass through the press before sampling. Running temperature was constantly monitored with a digital thermometer (TES Thermometer 1307 Type K) inserted into the restriction die. Pressing was carried out by using three different restriction dies $(10,12,14 \mathrm{~mm}$ 
for walnut; 12, 13, $14 \mathrm{~mm}$ for almond). After each run, all press devices were cleaned and dried.

\subsection{Oil recovery}

The oil yield (OY) was calculated considering the initial oil content in the incoming material (walnut or almond sifted materials) and the residual oil content in the pressed cake. It was expressed as $g$ extracted oil/g oil present in the incoming material $\mathrm{x}$ 100 (g/100 g oil). Oil contents from both sifted materials and pressed cakes were determined by extraction (10 h) using Soxhlet devices, with $n$-hexane as solvent, and expressed as weight percent on DB.

\subsection{Fines solid content in oil}

The screw-pressed oil samples were centrifuged at $11.000 \mathrm{~g}$ for $30 \mathrm{~min}$. The precipitated solids were recovered, washed with $n$-hexane, dried and weighed. Solid content was expressed as g solids/100 g extract (oil + solid) (Martínez et al., 2012).

\subsection{Oil analysis}

\subsubsection{Chemical quality parameters}

Free fatty acid content (FFAC), peroxide value $(\mathrm{PV})$, and specific extinction coefficients $\left(\mathrm{K}_{232}\right.$ and $\mathrm{K}_{270}$ ) were quantified according to standard methods of AOCS (2009).

\subsubsection{Fatty acid composition}

Fatty acid composition was analyzed by gas chromatography according to procedures reported earlier (Maestri et al., 2015). Briefly, oil samples of $0.5 \mathrm{~g}$ were subjected to alkaline saponification (1N KOH in methanol). Unsaponificable matter was extracted with $n$-hexane. The fatty acid methyl ester (FAME) of total lipids were obtained using $1 \mathrm{~N}$ $\mathrm{H}_{2} \mathrm{SO}_{4}$ in methanol and analyzed by gas chromatography (GC) (Perkin-Elmer, Shelton, CT, USA) using a fused silica capillary column ( $30 \mathrm{~m}$ x 0.25 $\mathrm{mm}$ i.d. x $0.25 \mathrm{~mm}$ film thickness) CP Wax $52 \mathrm{CB}$ (Varian, Walnut Creek, CA, USA); carrier gas $\mathrm{N}_{2}$ at $1 \mathrm{~mL} / \mathrm{min}$; split ratio 100:1; column temperature programmed from $180^{\circ} \mathrm{C}(5 \mathrm{~min})$ to $220^{\circ} \mathrm{C}$ at $2{ }^{\circ} \mathrm{C} /$ min; injector and detector temperatures at $250{ }^{\circ} \mathrm{C}$, FID. The identification of FAME was carried out by comparison of their retention times with those of reference compounds.

\subsubsection{Oxidative stability}

The oxidative stability index (OSI) was determined by the Rancimat (Metrohm, Herisau, Switzerland) method (Cd 12b-92 AOCS, 2009) using $3 \mathrm{~g}$ oil aliquots. The air flow rate was set at $20 \mathrm{~L} / \mathrm{h}$, and the temperature of the heating block was maintained at $110^{\circ} \mathrm{C}$. Results corresponded to the break points in the plotted curves and were expressed as induction time (in hours).

\subsection{Experimental design and response surface analysis}

Response surface methodology (RSM) was used to model and optimize the conditions of oil extraction for walnut and almonds fruits (Montgomery, 2005; Akinoso and Raji, 2011; Martínez et al., 2012; 2017; Martínez and Maestri, 2015). Experiments were planned by applying $3^{2}$ factorial designs (Montgomery, 2005). Three different levels were used for each of the following factors: seed moisture content (SMC) $\left(X_{1}\right)$ and restriction die (RD) $\left(X_{2}\right)$. The evaluated responses were: oil recovery (OY) $\left(Y_{1}\right)$, fine solid content $(\mathrm{FC})\left(Y_{2}\right)$, and regarding oil quality: peroxide value (PV) $\left(Y_{3}\right)$, free fatty acid content (FFAC) $\left(Y_{4}\right), \mathrm{K}_{232}\left(Y_{5}\right)$ and $\mathrm{K}_{270}\left(Y_{6}\right)$. Quadratic polynomials were fitted to express the responses $\left(Y_{n}\right)$ as a function of factors (Eq. 1); where $\mathrm{Y}$ is the response, $\beta_{0}$ is the constant term, $\beta_{i}$ represents the coefficients of the linear parameters, $X_{i}$ represents the factors, $\beta_{i i}$ represents the coefficients of the quadratic parameter, $\beta_{i j}$ represents the coefficients of the interaction parameters and $\varepsilon$ is the random error.

The results were analyzed by a multiple regression method. The experimental results were applied to obtain the regression models. The quality of the model fitness was evaluated by ANOVA. The fit of the model to the experimental data was given by the coefficient of determination, $\mathrm{R}^{2}$, which explains the extent of the variance in a modelled variable that can be explained with the model. Only models with high coefficient of determination were included in this study.

$Y=\beta_{0}+\sum_{i=1}^{k} \beta_{i} X_{i}+\sum_{i=1}^{k} \beta_{i i} X_{i}^{2}+\sum_{i=1}^{k-1} \sum_{j=1}^{k} \beta_{i j} X_{i} X_{j}+\varepsilon$ (1)

All determinations were performed at least in duplicate, randomly, and replicas of the central point were done to allow estimation of pure error as square sums. For walnut oil extraction, two different designs were carried out in order to define the adequate extraction conditions. For almond oil extraction, a single experimental design was done due to limitations in the physical behavior of the raw material and the screw press used. Under certain moisture contents the press was obstructed.

Statistical analyses were performed using Statgraphic Plus software (v5.1. USA). For model validation, the response variable (OY, $Y_{1}$ ) was measured, in triplicate, under optimal extraction conditions, and the absolute average deviation (AAD), 
the Bias factor (Bf), and the Accuracy factor (Af) were calculated according to Desobgo et al., (2015). Finally, the percentage error between the predicted and the experimental values were calculated according to Barrera et al., (2016).

\section{RESULTS AND DISCUSSION}

For walnut oil extraction, an experimental design of 13 treatments ( 5 central points) was conducted in the first instance using the factors and levels previously described (Table 1), based on results obtained from pilot scale press extraction (Martínez et al., 2008).

Figure 1 shows the most relevant effects on oil recovery. The two factors analyzed (SMC and RD) showed $p$-values lower than the level of significance $(\mathrm{p} \leq 0.05)$. OY and $\mathrm{FC}$ values were between $44.8-80.4 \%$ and $10.6-15.1 \%$, respectively (Table 1 ). Increasing SMC from 3 to $8 \%$ (WB) significantly increased OY. Similar trends were obtained at pilot scale extraction conditions (Martínez et al., 2008). By increasing SMC from 2.5 to $7.5 \%$ (WB) these authors observed an increase in walnut OY from 61.0 to $83.5 \%$ (at $25^{\circ} \mathrm{C}$ ), and from 64.7 to $89.3 \%$ (at $50{ }^{\circ} \mathrm{C}$ ). The positive effect of increasing water content on OY may be explained through an increasing expansion and breaking of cell structures which expedites oil release. Moreover, water has a barrel lubricant effect so it increases the plasticity of seed material and contributes to press feeding. In the present study, the highest OY $(80.4 \%)$ was obtained at $8 \% \mathrm{SMC}$ and $10 \mathrm{~mm} \mathrm{RD}$. This treatment showed one of the lowest FC (11.5\%), which is considered a positive trait since it facilitates subsequent operations of oil clarification. At $8 \% \mathrm{SMC}$, an increase in RD produced a significant reduction in OY (Fig. 2). This was due to insufficient compression of seed material during pressing, causing a lesser amount of oil to be diverted to the barrel openings.

All walnut oils obtained at the various extraction conditions had PV ranging between 0.55 and 1.60 meq $\mathrm{O}_{2} / \mathrm{kg}$ oil, and FFAC between 0.06 and 0.17 (g oleic acid/g oil). Specific extinction coefficient $\left(\mathrm{K}_{232}\right.$ and $\left.\mathrm{K}_{270}\right)$ values were within the ranges 1.93 2.23 and $0.16-0.19$, respectively. The oxidative stability was between 2.12 and 2.29 (hours). These data show that the different extraction treatments had minimal effects on chemical quality parameters and oxidative stability.

A quadratic polynomial was fitted to model the oil recovery response. The determination coefficient of the model was able to explain $95.9 \%$ of the data variability. The SMC had a positive linear effect on OY; on the contrary, RD had a negative linear effect. On the other hand, both the SMC and the cross effect SMC x RD showed negative quadratic effects (Table 2). Considering that the combination of factor levels which suggested a maximum in OY $(80.4 \%)$ coincides with one extreme of the factors discussed, a new experimental design was carried out in order to find the extraction conditions that maximize OY $\left(Y_{l}\right)$. The new $3^{2}$ Factorial design tested the effect of the incoming factors, SMC and

TABLE 1: First industrial scale $3^{2}$ factorial design. Effect of process variables on walnut oil yield and quality parameters

\begin{tabular}{|c|c|c|c|c|c|c|c|c|c|}
\hline \multirow[b]{2}{*}{ Assay } & \multicolumn{2}{|c|}{ Factors $^{\mathrm{a}}$} & \multirow{2}{*}{ OY } & \multirow{2}{*}{ FC } & \multirow{2}{*}{ PV } & \multirow{2}{*}{ FFAC } & \multirow{2}{*}{$K_{232}$} & \multirow{2}{*}{$K_{270}$} & \multirow{2}{*}{ OSI } \\
\hline & $\mathrm{X}_{1}$ & $\mathbf{X}_{2}$ & & & & & & & \\
\hline 1 & 5.50 & 14 & $55.6 \pm 0.1$ & $15.1 \pm 0.1$ & $0.94 \pm 0.23$ & $0.12 \pm 0.05$ & $0.16 \pm 0.01$ & $1.94 \pm 0.02$ & $2.16 \pm 0.09$ \\
\hline 2 & 3.00 & 14 & $44.8 \pm 0.1$ & $11.2 \pm 0.1$ & $1.05 \pm 0.22$ & $0.07 \pm 0.02$ & $0.16 \pm 0.01$ & $1.94 \pm 0.01$ & $2.12 \pm 0.07$ \\
\hline 3 & 8.00 & 12 & $67.5 \pm 0.1$ & $13.6 \pm 0.1$ & $0.70 \pm 0.08$ & $0.06 \pm 0.05$ & $0.16 \pm 0.01$ & $1.96 \pm 0.02$ & $2.21 \pm 0.01$ \\
\hline 4 & 5.50 & 10 & $73.3 \pm 1.4$ & $13.1 \pm 1.1$ & $0.81 \pm 0.21$ & $0.06 \pm 0.01$ & $0.17 \pm 0.01$ & $2.13 \pm 0.10$ & $2.17 \pm 0.05$ \\
\hline $5^{\mathrm{b}}$ & 5.50 & 12 & $56.3 \pm 0.1$ & $14.8 \pm 0.1$ & $0.65 \pm 0.01$ & $0.07 \pm 0.01$ & $0.16 \pm 0.01$ & $1.93 \pm 0.01$ & $2.26 \pm 0.03$ \\
\hline $6^{b}$ & 5.50 & 12 & $57.3 \pm 1.6$ & $13.9 \pm 1.1$ & $0.70 \pm 0.22$ & $0.08 \pm 0.01$ & $0.16 \pm 0.01$ & $1.94 \pm 0.01$ & $2.26 \pm 0.07$ \\
\hline $7^{\mathrm{b}}$ & 5.50 & 12 & $55.1 \pm 0.2$ & $14.7 \pm 0.1$ & $0.82 \pm 0.24$ & $0.12 \pm 0.01$ & $0.16 \pm 0.01$ & $1.95 \pm 0.01$ & $2.27 \pm 0.09$ \\
\hline $8^{b}$ & 5.50 & 12 & $56.8 \pm 0.1$ & $15.1 \pm 0.1$ & $0.55 \pm 0.16$ & $0.14 \pm 0.01$ & $0.16 \pm 0.01$ & $1.94 \pm 0.01$ & $2.29 \pm 0.01$ \\
\hline $9^{\mathrm{b}}$ & 5.50 & 12 & $55.5 \pm 0.1$ & $14.2 \pm 0.1$ & $0.50 \pm 0.14$ & $0.10 \pm 0.01$ & $0.16 \pm 0.01$ & $1.97 \pm 0.01$ & $2.19 \pm 0.10$ \\
\hline 10 & 8.00 & 10 & $80.4 \pm 0.9$ & $11.5 \pm 1.4$ & $0.92 \pm 0.17$ & $0.07 \pm 0.01$ & $0.19 \pm 0.01$ & $2.23 \pm 0.10$ & $2.23 \pm 0.02$ \\
\hline 11 & 8.00 & 14 & $63.0 \pm 0.1$ & $14.2 \pm 0.1$ & $0.93 \pm 0.08$ & $0.17 \pm 0.01$ & $0.15 \pm 0.01$ & $1.98 \pm 0.01$ & $2.17 \pm 0.05$ \\
\hline 12 & 3.00 & 10 & $45.7 \pm 1.0$ & $12.6 \pm 1.1$ & $1.60 \pm 0.29$ & $0.06 \pm 0.01$ & $0.18 \pm 0.01$ & $2.09 \pm 0.02$ & $2.20 \pm 0.08$ \\
\hline 13 & 3.00 & 12 & $44.9 \pm 1.0$ & $10.6 \pm 0.1$ & $0.76 \pm 0.15$ & $0.07 \pm 0.01$ & $0.17 \pm 0.01$ & $2.01 \pm 0.03$ & $2.28 \pm 0.09$ \\
\hline
\end{tabular}

${ }^{a} \mathrm{X}_{1}$, seed moisture content $\left(\mathrm{g} / 100 \mathrm{~g}\right.$ seed, WB); $\mathrm{X}_{2}$, restriction die $(\mathrm{mm})$; OY, oil yield $(\mathrm{g} / 100 \mathrm{~g}$ oil); FC, fine solid content in oil (g solids/100 g extract); PV, peroxide value (meq/kg oil); FFAC, free fatty acid content (g oleic acid/g oil); OSI, oxidative stability index (hours). Values are expressed as arithmetic mean \pm standard deviation $(\mathrm{n}=2) .{ }^{\mathrm{b}}$ Central points. 


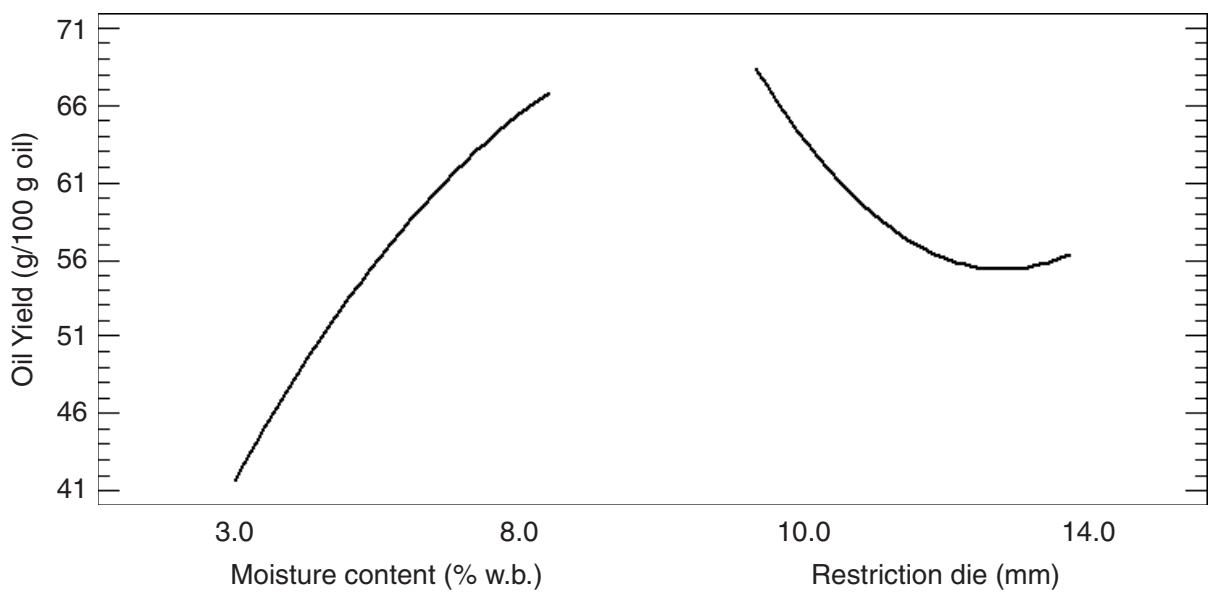

FIgURE 1. Main significant effects on oil yield in walnut oil extraction (First design).

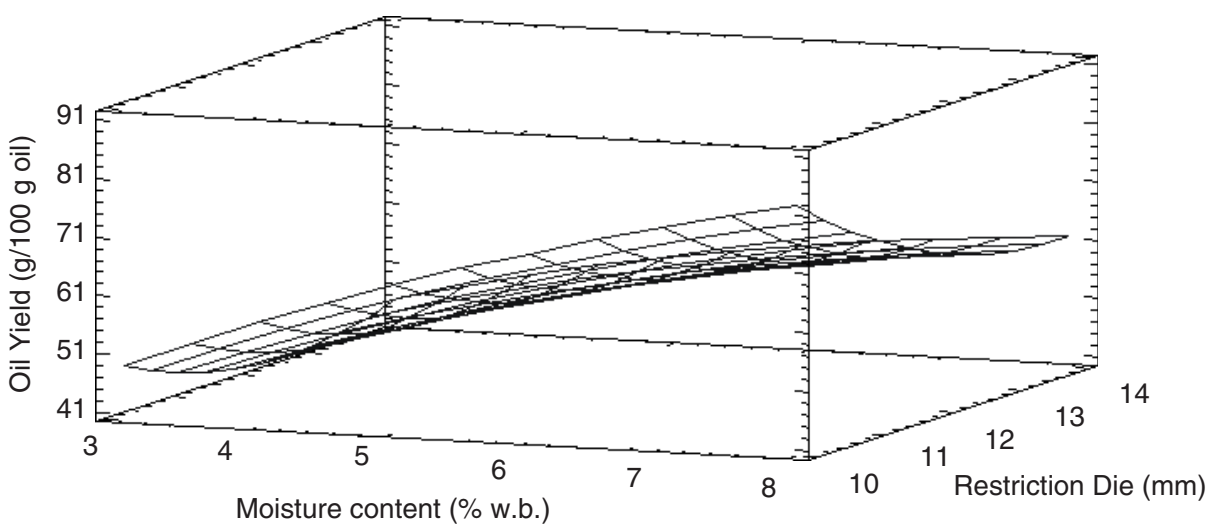

FIGURE 2. Effects of seed moisture content and restriction die on walnut oil yield (First design).

$\mathrm{RD}$, in 13 experiments ( 5 central points). The experimental design and the response variables considered are shown in Table 3.

To sum up at this point, it can be concluded that the different treatments employed for walnut oil extractions had minimal effects on the chemical quality parameters analyzed, but OY was largely affected. A quadratic polynomial was fitted to model the oil recovery response. The determination coefficient of the model was able to explain $94.5 \%$ of the data variability. The SMC had a positive linear effect, while RD had a negative linear effect on OY. SMC and RD had negative and positive quadratic effects. A positive cross effect was observed between SMC and RD (Table 2). The combination of factor levels that suggests maximum OY and minimum FC coincides with the treatment number $2(7.75 \%$ SMC (WB) and $10 \mathrm{~mm} \mathrm{RD)}$ (Fig 3). The predicted value (81.5\%) and the experimental value $(84.5 \pm 2.3 \%)$ showed an error of $3.7 \%$, thus suggesting a good prediction level of the model.
Even though an OY value of $84.5 \%$ is lower than that obtained at pilot scale extraction conditions (89.3\%, Martínez et al., 2008), it is a promising value since it provides around $515 \mathrm{~g}$ oil per $\mathrm{kg}$ of milled and hydrated material. When the extraction yield (oil recovery, OY) is evaluated as a function of the two process variables (SMC and RD), a maximum is observed at a moisture contents near 7.50\% (WB) which coincides with results from pilot scale conditions (Martínez et al., 2008) (Fig 4). The maximum OR is obtained with relatively small reduction $(10 \mathrm{~mm})$ which provides a good relationship between the fluidity and compression of the material without generating clogging.

Chemical analyses showed PV, FFAC, $\mathrm{K}_{232}$ and $\mathrm{K}_{270}$ values ranging between $0.65-1.14 \mathrm{meq} \mathrm{O} / \mathrm{kg}$ oil, $0.06-0.17$ (g oleic acid/g oil), $1.93-2.23$ and $0.15-0.19$, respectively; while the oxidative stability ranged from 2.16 to 2.28 (hours). These results were similar to those obtained using the first experimental design. In addition, the oil obtained at the optimum extraction condition showed an OSI value 
TABLE 2: Values of regression coefficients calculated for walnut and almond oil yield

\begin{tabular}{|c|c|c|c|}
\hline $\begin{array}{l}\text { Independent } \\
\text { variable }\end{array}$ & $\begin{array}{l}\text { Regression } \\
\text { coefficient }\end{array}$ & $\begin{array}{l}\text { Standard } \\
\text { error }\end{array}$ & $\begin{array}{l}\text { Significance } \\
\text { level (p) }\end{array}$ \\
\hline \multicolumn{4}{|c|}{ Walnut - First Design } \\
\hline Constant & 186.897 & & \\
\hline $\mathrm{X}_{1}$ & 20.0525 & 2.3012 & 0.0000 \\
\hline $\mathrm{X}_{2}$ & -30.1321 & 2.3012 & 0.0012 \\
\hline $\mathrm{X}_{1}{ }^{2}$ & -0.4657 & 3.3917 & 0.1300 \\
\hline $\mathrm{X}_{2}{ }^{2}$ & 1.3195 & 3.3917 & 0.0170 \\
\hline $\mathrm{X}_{1} * \mathrm{X}_{2}$ & -0.8244 & 2.8183 & 0.0222 \\
\hline $\mathrm{R}^{2}$ & & & 95.9 \\
\hline \multicolumn{4}{|c|}{ Walnut - Second Design } \\
\hline Constant & 430,864 & & \\
\hline $\mathrm{X}_{1}$ & 4,0643 & 1.6876 & 0.0490 \\
\hline $\mathrm{X}_{2}$ & $-61,5551$ & 1.6876 & 0.0002 \\
\hline $\mathrm{X}_{1}{ }^{2}$ & $-0,9305$ & 2.4874 & 0.0068 \\
\hline $\mathrm{X}_{2}^{2}$ & 2,1376 & 2.4874 & 0.0002 \\
\hline $\mathrm{X}_{1} * \mathrm{X}_{2}$ & 0,9362 & 2.0669 & 0.0047 \\
\hline $\mathrm{R}^{2}$ & & & 94.5 \\
\hline AAD & & & 0.034 \\
\hline $\mathrm{Bf}$ & & & 0.966 \\
\hline Af & & & 1.035 \\
\hline \multicolumn{4}{|l|}{ Almond } \\
\hline Constant & -577.904 & 1.0633 & \\
\hline $\mathrm{X}_{1}$ & 58.6122 & 2.0909 & 0.0124 \\
\hline $\mathrm{X}_{2}$ & 62.4494 & 2.0909 & 0.0009 \\
\hline $\mathrm{X}_{1}^{2}$ & -3.2982 & 3.0817 & 0.0696 \\
\hline $\mathrm{X}_{2}{ }^{2}$ & -2.7387 & 3.0817 & 0.1187 \\
\hline $\mathrm{X}_{1} * \mathrm{X}_{2}$ & 0.2970 & 2.5608 & 0.8232 \\
\hline $\mathrm{R}^{2}$ & & & 88.6 \\
\hline AAD & & & 0.039 \\
\hline $\mathrm{Bf}$ & & & 0.976 \\
\hline Af & & & 1.025 \\
\hline
\end{tabular}

${ }^{\mathrm{a}} \mathrm{X}_{1}$ : seed moisture $(\mathrm{g} / 100 \mathrm{~g}$ seed, $\mathrm{WB}) . \mathrm{X}_{2}$ : restriction die $(\mathrm{mm})$. AAD: absolute average deviation. Bf: bias factor. Af: accuracy factor.

$(2.09 \pm 0.08 \mathrm{~h})$ and FA percentages (palmitic acid, $7.03 \pm 1.30 \%$; palmitoleic acid, $0.06 \pm 0.00 \%$; stearic acid, $2.72 \pm 0.20 \%$; oleic acid, $19.3 \pm 2.01 \%$; linoleic acid, $56.7 \pm 1.68 \%$ and linolenic acid, $14.2 \pm$ $0.12 \%)$ in accordance with those reported elsewhere (Martinez et al., 2006; Martinez et al., 2010).

On the basis of the results obtained under pilot scale extraction conditions (Martínez et al., 2013), a preliminary exploratory experimental study (data not shown) using the industrial screw-press in which the behavior of the almond with a moisture content of $8 \%, 10 \%$ and $12 \%$ (w.b.) and a restriction die of $10 \mathrm{~mm}$ was evaluated. The results showed that, under those process conditions, the clogging of the material inside the press occurred, so an experimental design of 13 treatments ( 5 central points) was conducted for almond oil extraction, using the factors and levels described in Table 4.

Figure 5 shows the most relevant effects on oil recovery. The two factors analyzed (SMC and RD) showed p-values lower than the level of significance $(\mathrm{p} \leq 0.05)$. OY and FC values were between $49.2-$ $70.2 \%$ and $8.6-11.0 \%$, respectively (Table 4$)$. The treatment at $10 \% \mathrm{SMC}(\mathrm{WB})-12 \mathrm{~mm}$ RD gave the highest OY (Figure 6) and the lowest FC (9.9\%). Chemical parameters and oxidative stability were not significantly affected by the different extraction conditions tested. PV, FFAC, $\mathrm{K}_{232}, \mathrm{~K}_{270}$ and OSI values were lower than 0.09 meq $\mathrm{O}_{2} / \mathrm{kg}$ oil, $0.02 \mathrm{~g}$ oleic acid/g oil, 1.72, 0.05 and 12.9 hours, respectively.

A quadratic polynomial was fitted to model the oil recovery response. The determination coefficient of the model was able to explain $88.6 \%$ of the data variability. Both the SMC and RD had a positive linear effect and a quadratic negative effect on OY. Also, a positive cross effect was observed between SMC and RD (Table 2). The combination of factor levels which suggested a maximum on OY and a minimum in $\mathrm{FC}$ within the experimental values tested was $9.42 \%$ SMC (WB) and RD $12 \mathrm{~mm}$. The result demonstrates that the regression equation allowed an accurate prediction of OY. The predicted value $(70.1 \%)$ and experimental value $(71.9 \pm 3.5 \%)$ presented an error of $2.6 \%$, thus suggesting a good prediction level for the model. The oil obtained at this condition showed a OSI value $(13.01 \pm 0.85$ h) and fatty acid composition (palmitic acid, 6.65 $\pm 1.23 \%$; palmitoleic acid, $0.43 \pm 0.04 \%$; stearic acid, $0.72 \pm 0.06 \%$; oleic acid, $71.90 \pm 2.45 \%$; linoleic acid, $20.30 \pm 1.32 \%$ and linolenic acid, $0.06 \pm$ $0.00 \%$ in accordance with data reported elsewhere (Martinez et al., 2013).

The evaluation of the real performance of the predictive models obtained for both walnut and almond oil extraction was done according to Desobgo et al., (2015). According to these authors, a perfect agreement between observed and predicted responses is related to $\mathrm{Bf}$ and $\mathrm{Af}$ values of 1 and AAD of 0 . The correlation coefficients associated with $\mathrm{AAD}, \mathrm{Bf}$, and $\mathrm{Af}$ values allowed validation of the models, as shown in Table 2.

\section{CONCLUSIONS}

$3^{2}$ Factorial designs were used to optimize walnut and almond oil extractions by means of screw-pressing operations. Experimental designs included seed moisture content (SMC) and restriction die (RD) as the main processing parameters. Theoretical models were scanned against experimental data in order to scale-up the proposed oil extraction process to industrial scale. For both extraction processes, fitted models for oil recovery showed maximum predicted 
Walnut and almond oil screw-press extraction at industrial scale: Effects of process parameters on oil yield and quality $\bullet$

TABLE 3: Second industrial scale $3^{2}$ factorial design. Effect of process variables on walnut oil yield and quality parameters

\begin{tabular}{|c|c|c|c|c|c|c|c|c|c|}
\hline \multirow[b]{2}{*}{ Assay } & \multicolumn{2}{|c|}{ Factors $^{\mathrm{a}}$} & \multirow{2}{*}{ OY } & \multirow{2}{*}{ FC } & \multirow{2}{*}{ PV } & \multirow{2}{*}{ FFAC } & \multirow{2}{*}{$\mathbf{K}_{232}$} & \multirow{2}{*}{$K_{270}$} & \multirow{2}{*}{ OSI } \\
\hline & $X_{1}$ & $\mathbf{X}_{2}$ & & & & & & & \\
\hline 1 & 10.00 & 12 & $60.6 \pm 0.1$ & $13.9 \pm 0.1$ & $1.04 \pm 0.22$ & $0.06 \pm 0.01$ & $0.18 \pm 0.01$ & $2.12 \pm 0.01$ & $2.28 \pm 0.01$ \\
\hline 2 & 7.75 & 10 & $80.7 \pm 1.6$ & $10.9 \pm 1.0$ & $0.88 \pm 0.03$ & $0.05 \pm 0.01$ & $0.16 \pm 0.02$ & $1.97 \pm 0.08$ & $2.16 \pm 0.12$ \\
\hline 3 & 5.50 & 10 & $73.3 \pm 1.4$ & $13.1 \pm 1.1$ & $0.81 \pm 0.21$ & $0.06 \pm 0.01$ & $0.17 \pm 0.01$ & $2.13 \pm 0.10$ & $2.27 \pm 0.02$ \\
\hline 4 & 10.0 & 10 & $68.6 \pm 0.1$ & $12.8 \pm 0.1$ & $1.14 \pm 0.23$ & $0.08 \pm 0.01$ & $0.17 \pm 0.01$ & $2.11 \pm 0.04$ & $2.17 \pm 0.01$ \\
\hline $5^{b}$ & 7.75 & 12 & $63.3 \pm 3.7$ & $15.1 \pm 1.3$ & $0.85 \pm 0.26$ & $0.07 \pm 0.01$ & $0.18 \pm 0.02$ & $2.04 \pm 0.06$ & $2.18 \pm 0.03$ \\
\hline $6^{\mathrm{b}}$ & 7.75 & 12 & $60.4 \pm 0.1$ & $16.5 \pm 0.1$ & $0.75 \pm 0.10$ & $0.07 \pm 0.01$ & $0.19 \pm 0.02$ & $2.09 \pm 0.03$ & $2.19 \pm 0.08$ \\
\hline $7^{\mathrm{b}}$ & 7.75 & 12 & $62.2 \pm 2.5$ & $14.7 \pm 0.9$ & $1.09 \pm 0.32$ & $0.07 \pm 0.01$ & $0.17 \pm 0.01$ & $2.07 \pm 0.03$ & $2.26 \pm 0.01$ \\
\hline $8^{b}$ & 7.75 & 12 & $63.3 \pm 1.6$ & $15.7 \pm 1.3$ & $0.81 \pm 0.16$ & $0.07 \pm 0.01$ & $0.18 \pm 0.02$ & $2.04 \pm 0.10$ & $2.28 \pm 0.02$ \\
\hline $9^{b}$ & 7.75 & 12 & $63.0 \pm 1.8$ & $14.9 \pm 1.3$ & $0.81 \pm 0.12$ & $0.07 \pm 0.01$ & $0.17 \pm 0.01$ & $2.03 \pm 0.07$ & $2.21 \pm 0.09$ \\
\hline 10 & 5.50 & 12 & $57.1 \pm 0.6$ & $13.8 \pm 0.3$ & $0.58 \pm 0.06$ & $0.10 \pm 0.02$ & $0.18 \pm 0.01$ & $1.88 \pm 0.03$ & $2.25 \pm 0.01$ \\
\hline 11 & 7.75 & 14 & $61.6 \pm 0.3$ & $13.7 \pm 0.6$ & $0.89 \pm 0.05$ & $0.11 \pm 0.01$ & $0.17 \pm 0.01$ & $2.06 \pm 0.11$ & $2.22 \pm 0.03$ \\
\hline 12 & 10.0 & 14 & $67.8 \pm 0.1$ & $13.1 \pm 0.1$ & $1.09 \pm 0.01$ & $0.07 \pm 0.01$ & $0.17 \pm 0.01$ & $2.10 \pm 0.03$ & $2.17 \pm 0.04$ \\
\hline 13 & 5.50 & 14 & $54.8 \pm 0.1$ & $14.7 \pm 0.1$ & $0.90 \pm 0.18$ & $0.12 \pm 0.02$ & $0.15 \pm 0.02$ & $1.93 \pm 0.05$ & $2.28 \pm 0.02$ \\
\hline
\end{tabular}

${ }^{\mathrm{a}} \mathrm{X}_{1}$, seed moisture content $(\mathrm{g} / 100 \mathrm{~g}$ seed, $\mathrm{WB}) ; \mathrm{X}_{2}$, restriction die $(\mathrm{mm})$; OY, oil yield $(\mathrm{g} / 100 \mathrm{~g}$ oil); FC, fine solid content in oil ( $\mathrm{g}$ solids $/ 100 \mathrm{~g}$ extract); PV, peroxide value (meq/kg oil); FFAC, free fatty acid content ( $\mathrm{g}$ oleic acid/g oil); OSI, oxidative stability index (hours). Values are expressed as arithmetic mean \pm standard deviation $(\mathrm{n}=2) .{ }^{\mathrm{b}}$ Central points.

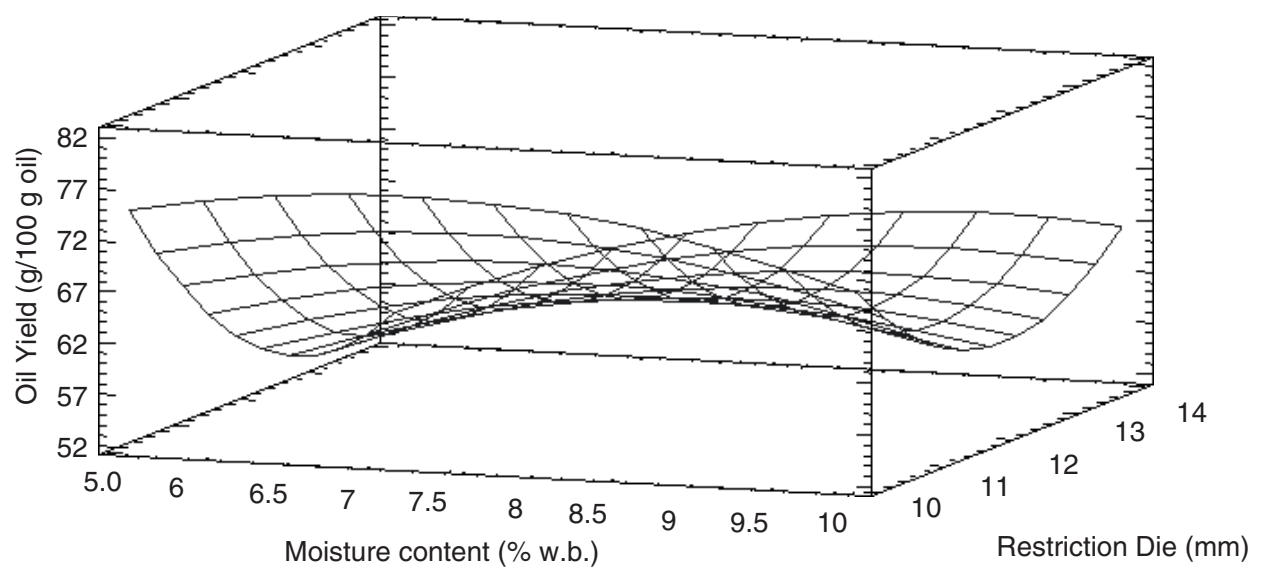

FIGURE 3. Effects of seed moisture content and restriction die on walnut oil yield (Second design).

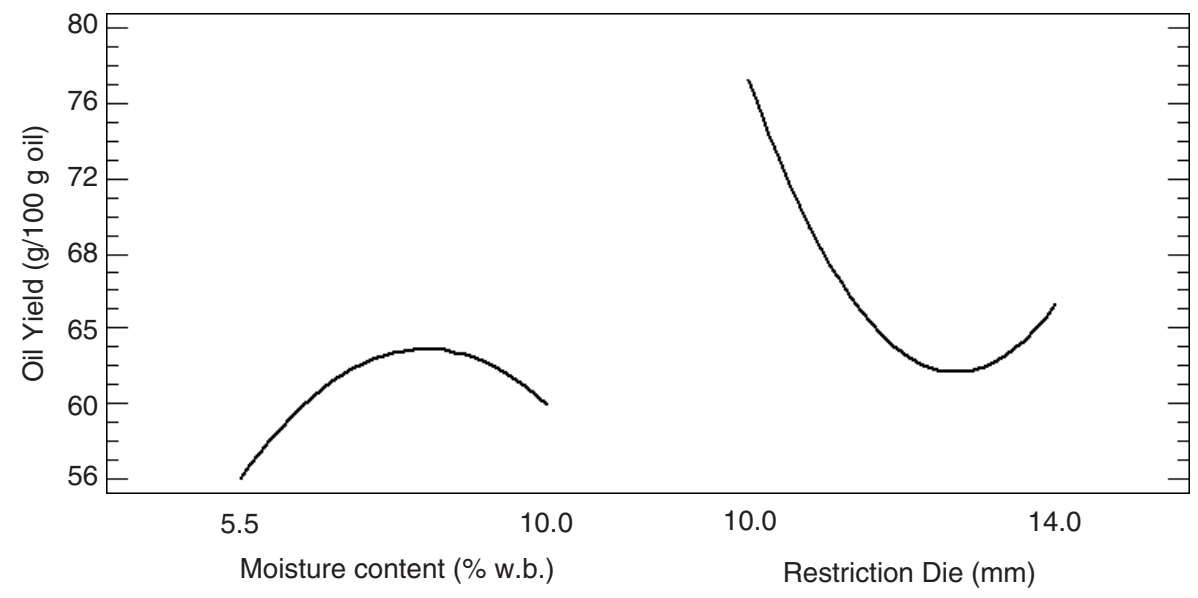

FIGURE 4. Main significant effects on oil yield in walnut oil extraction (Second design). 
• M.L. Martínez, M.G. Bordón, R.M. Bodoira, M.C. Penci, P.D. Ribotta and D.M. Maestri

TABLE 4: Industrial scale $3^{2}$ factorial design. Effect of process variables on almond oil yield and quality parameters

\begin{tabular}{|c|c|c|c|c|c|c|c|c|c|}
\hline \multirow{2}{*}{ Assay } & \multicolumn{2}{|c|}{ Factors $^{\mathrm{a}}$} & \multirow{2}{*}{ OY } & \multirow{2}{*}{ FC } & \multirow{2}{*}{ PV } & \multirow{2}{*}{ FFAC } & \multirow{2}{*}{$K_{232}$} & \multirow{2}{*}{$\mathbf{K}_{270}$} & \multirow{2}{*}{ OSI } \\
\hline & $\mathrm{X}_{1}$ & $X_{2}$ & & & & & & & \\
\hline 1 & 11.00 & 14 & $49.2 \pm 1.0$ & $10.3 \pm 0.1$ & ND & $0.41 \pm 0.02$ & $1.41 \pm 0.01$ & $0.05 \pm 0.01$ & $11.6 \pm 0.02$ \\
\hline 2 & 9.00 & 14 & $55.1 \pm 2.1$ & $11.0 \pm 0.2$ & ND & $0.33 \pm 0.04$ & $1.30 \pm 0.02$ & $0.05 \pm 0.01$ & $11.8 \pm 0.04$ \\
\hline 3 & 9.00 & 13 & $69.3 \pm 1.8$ & $9.9 \pm 0.1$ & $0.04 \pm 0.00$ & $0.35 \pm 0.03$ & $1.27 \pm 0.02$ & $0.05 \pm 0.01$ & $11.7 \pm 0.04$ \\
\hline 4 & 11.00 & 12 & $61.7 \pm 1.6$ & $9.1 \pm 0.1$ & $0.05 \pm 0.00$ & $0.44 \pm 0.13$ & $1.33 \pm 0.01$ & $0.04 \pm 0.01$ & $10.9 \pm 0.08$ \\
\hline $5^{b}$ & 10.00 & 13 & $64.7 \pm 1.0$ & $9.2 \pm 0.6$ & $0.04 \pm 0.00$ & $0.37 \pm 0.06$ & $1.27 \pm 0.06$ & $0.05 \pm 0.01$ & $12.1 \pm 0.05$ \\
\hline $6^{\mathrm{b}}$ & 10.00 & 13 & $65.2 \pm 1.3$ & $9.8 \pm 0.4$ & $0.02 \pm 0.00$ & $0.38 \pm 0.05$ & $1.24 \pm 0.06$ & $0.05 \pm 0.01$ & $12.2 \pm 0.01$ \\
\hline $7^{\mathrm{b}}$ & 10.00 & 13 & $64.9 \pm 1.6$ & $9.9 \pm 0.6$ & $0.03 \pm 0.00$ & $0.40 \pm 0.04$ & $1.23 \pm 0.05$ & $0.05 \pm 0.01$ & $12.1 \pm 0.01$ \\
\hline $8^{b}$ & 10.00 & 13 & $65.5 \pm 2.4$ & $9.5 \pm 0.6$ & $0.03 \pm 0.00$ & $0.36 \pm 0.05$ & $1.25 \pm 0.04$ & $0.05 \pm 0.01$ & $12.2 \pm 0.02$ \\
\hline $9^{b}$ & 10.00 & 13 & $65.0 \pm 1.9$ & $8.6 \pm 0.6$ & $0.05 \pm 0.01$ & $0.41 \pm 0.06$ & $1.36 \pm 0.06$ & $0.04 \pm 0.01$ & $12.7 \pm 0.04$ \\
\hline 10 & 9.00 & 12 & $68.7 \pm 1.4$ & $9.0 \pm 0.1$ & ND & $0.47 \pm 0.08$ & $1.32 \pm 0.10$ & $0.05 \pm 0.01$ & $12.1 \pm 0.06$ \\
\hline 11 & 10.00 & 14 & $61.5 \pm 1.4$ & $10.2 \pm 0.1$ & $0.04 \pm 0.00$ & $0.39 \pm 0.06$ & $1.28 \pm 0.01$ & $0.05 \pm 0.01$ & $12.1 \pm 0.07$ \\
\hline 12 & 10.00 & 12 & $70.2 \pm 2.3$ & $9.9 \pm 0.3$ & $0.09 \pm 0.01$ & $0.37 \pm 0.02$ & $1.72 \pm 0.04$ & $0.05 \pm 0.01$ & $12.9 \pm 0.09$ \\
\hline 13 & 11.00 & 13 & $61.2 \pm 1.1$ & $9.5 \pm 0.2$ & $0.06 \pm 0.01$ & $0.39 \pm 0.04$ & $1.35 \pm 0.02$ & $0.04 \pm 0.01$ & $12.4 \pm 0.01$ \\
\hline
\end{tabular}

${ }^{a} \mathrm{X}_{1}$, seed moisture content $(\mathrm{g} / 100 \mathrm{~g}$ seed, $\mathrm{WB}) ; \mathrm{X}_{2}$, restriction die $(\mathrm{mm})$; OY, oil yield $(\mathrm{g} / 100 \mathrm{~g}$ oil); FC, fine solid content in oil (g solids/100 g extract); PV: peroxide value (meq/kg oil); FFAC: free fatty acid content (g oleic acid/g oil); OSI: oxidative stability index (hours). Values are expressed as arithmetic mean \pm standard deviation $(n=2)$. ND: not detected. ${ }^{b}$ Central points

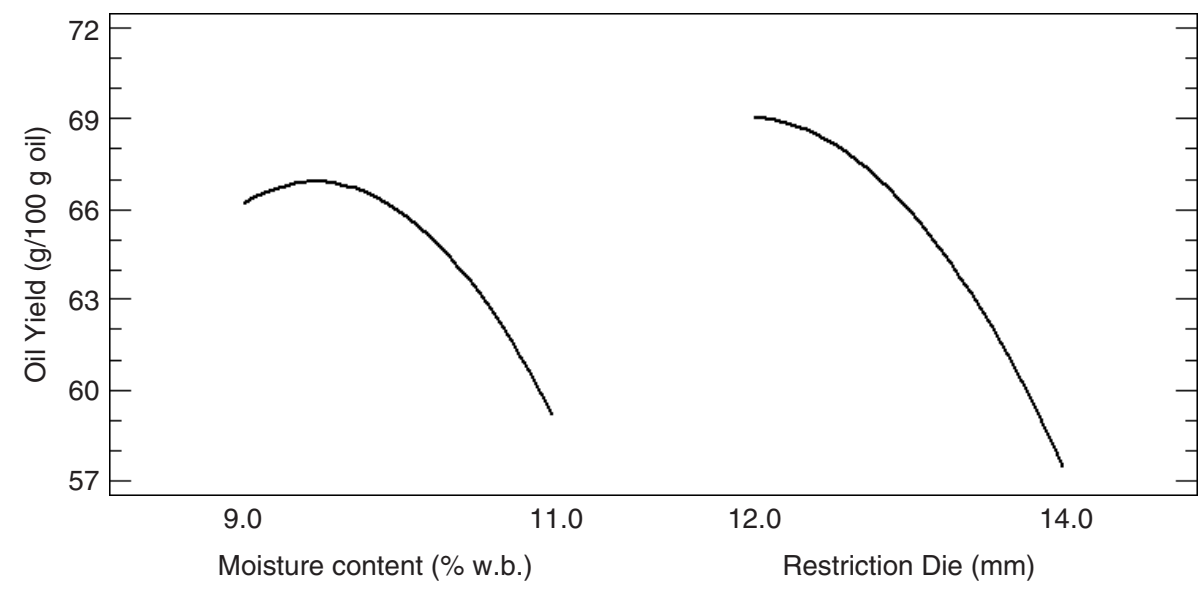

FIGURE 5. Main significant effects on oil yield in almond oil extraction.

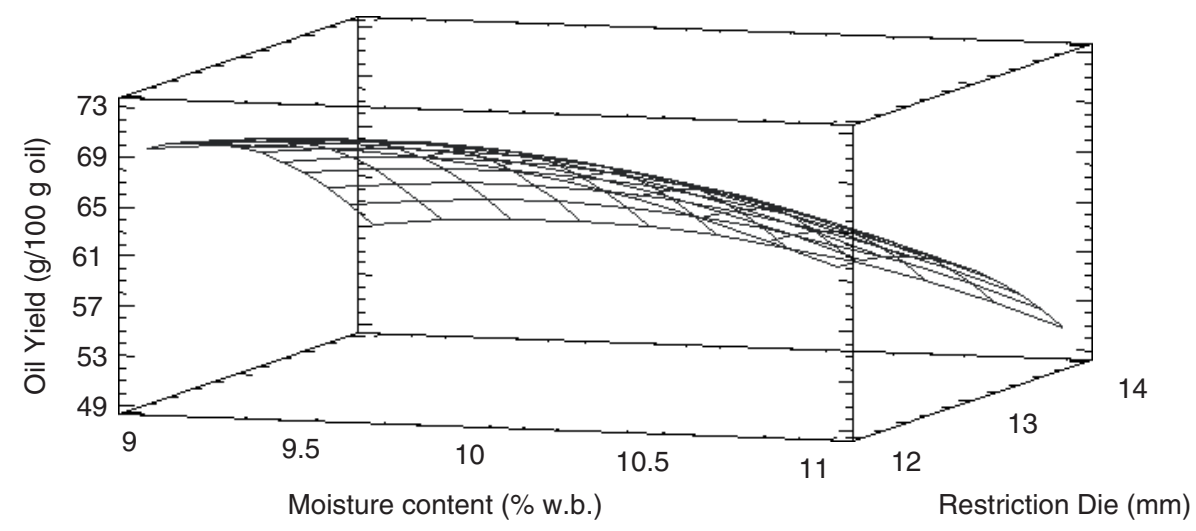

FIGURE 6. Effects of seed moisture content and restriction die on almond oil yield. 
values similar to the highest experimental values, which were reached under the following conditions: 7.75\% SMC, $10 \mathrm{~mm} \mathrm{RD} \mathrm{(walnut} \mathrm{oil),} \mathrm{and} \mathrm{9.42 \%}$ SMC, $12 \mathrm{~mm}$ RD (almond oil). Chemical quality parameters of the oils obtained at these conditions were in the ranges stated in the Codex (FAO/WHO) standards for non-refined oils.

\section{ACKNOWLEDGMENTS}

This research was financed with grants from Consejo de Investigaciones Científicas y Técnicas (CONICET), Secretaría de Ciencia y Tecnología de la Universidad Nacional de Córdoba (SeCyT B 203/14),Fund for Scientific Research and Technology (FONCyT - BID PICT 2014-2283) and Secretaría de Políticas Universitarias (SPUMinisterio de Educación) from Argentina.

\section{REFERENCES}

Akinoso R, Raji AO. 2011. Optimization of oil extraction from locust bean using response surface methodology. Eur. J. Lipid Sci. Technol. 113, 245-252. http://dx.doi.org/10.1002/ ejlt.201000354

Barrera GN, Tadini CC, León AE, Ribotta PD. 2016. Use of alpha-amylase and amyloglucosidase combinations to minimize the bread quality problems caused by high levels of damaged starch. J. Food Sci. Technol. 53, 3675-3684. http://dx.doi.org/10.1007/s13197-016-2337-2

Desobgo ZSC, Stafford RA, Metcalfe DJA. 2015. Dimethyl sulfide stripping behavior during wort boiling using response surface methodology. J. $A S B C$. 1, 84-89. http://dx.doi. org/10.1094/ASBCJ-2015-0103-01

Hamm W, Hamilton RJ. 2000. The production of oils in Edible Oil Processing. Sheffield Academic Press, England.

Kodad O, Socias I, Company R. 2008. Variability of oil content and major fatty acid composition in almond (Prunus amygdalus Batsch) and its relationship with kernel quality. J. Agric. Food Chem. 56, 4096-4101. http://pubs.acs.org/ doi/abs/10.1021/jf8001679

Maestri D, Martínez M, Bodoira R, Rossi Y, Oviedo A, Pierantozzi P, Torres M. 2015. Variability in almond oil chemical traits from traditional cultivars and native genetic resources from Argentina. Food Chem. 170, 55- 61. https:// doi.org/10.1016/j.foodchem.2014.08.073

Martínez ML, Mattea MA, Maestri DM. 2006. Varietal and crop year effects on lipid composition of walnut (Juglans regia) genotypes. J. Am. Oil Chem. Soc. 83, 791-796. https://doi.org/10.1007/s11746-006-5016-z

Martínez ML, Mattea MA, Maestri DM. 2008. Pressing and supercritical carbon dioxide extraction of walnut oil. J. Food Eng. 88, 399-404. https://doi.org/10.1016/j. jfoodeng.2008.02.026

Martinez ML, Labuckas DO, Lamarque AL, Maestri, DM. 2010. Walnut (Juglans regia L.): genetic resources, chemistry and by-products. J. Sci. Food Agric. 90, 1959-1967. https://doi.org/10.1002/jsfa.4059

Martínez ML, Marín MA, Salgado Faller CM, Revol J, Penci MC, Ribotta PD. 2012. Chia (Salvia hispanica L.) oil extraction: study of processing parameters. J. Food Sci. Technol. 47, 78-82. https://doi.org/10.1016/j.lwt.2011.12.032

Martínez ML, Penci MC, Marin MA, Ribotta PD, Maestri DM. 2013. Screw press extraction of almond (Prunus dulcis (Miller) D.A. Webb): Oil recovery and oxidative stability. J. Food Eng. 119, 40-45. https://doi.org/10.1016/j. jfoodeng.2013.05.010

Martínez ML, Bordón MG, Lallana RL, Ribotta PD, Maestri DM. 2017. Optimization of Sesame Oil Extraction by Screw-Pressing at Low Temperature. Food Biop. Technol. 10, 1113-1121. https://doi.org/10.1007/s11947-017-1885-4

Martínez M, Maestri D. 2015. Aceites vegetales no tradicionales "Guía para la producción y evaluación de la calidad". Grupo Editor Encuentro, Córdoba.

Montgomery, DC. 2005. Introduction to factorial designs, in Montgomery DC (Ed.) Design and Analysis of Experiments. John Wiley \& Sons Inc., New York, pp. 160-197.

Owolarafe OK, Faborode MO, Obafemi OA. 2002. Comparative evaluation of the digester-screw press and a hand-operated hydraulic press for palm fruit processing. J. Food Eng. 52, 249-255. https://doi.org/10.1016/S0260-8774(01)00112-1

Savoire R, Lanoisellé JL, Vorobiev E. 2013. Mechanical continuous oil expression from oilseeds: a review. Food Biop. Technol.6, 1-16. https://doi.org/10.1007/s11947-012-0947-x

Singh J, Bargale PC. 1990. Mechanical expression of oil from linseed. J. Oilseeds Res. 7, 106-110.

Singh J, Bargale PC. 2000. Development of a small capacity double stage compression screw press for oil expression. J. Food Eng. 43, 75-82. https://doi.org/10.1016/ S0260-8774(99)00134-X

Singh KK, Wiesenborn DP, Tostenson K, Kangas N. 2002. Influence of moisture content and cooking on screw pressing of crambe seed. J. Am. Oil Chem. Soc. 79, 165-170. https://doi.org/10.1007/s11746-002-0452-3

Wiesenborn D, Doddapaneni R, Tostenson K, Kangas N. 2001. Cooking indices to predict screw-press performance for crambe seed. J. Am. Oil Chem. Soc. 78, 467-471. https:// doi.org/10.1007/s11746-001-0287-y

Zheng Y, Wiesenborn DP, Tostenson K, Kangas N. 2003. Screw pressing of whole and dehulled flaxseed for organic oil. $J$. Am. Oil Chem. Soc. 80, 1039-1045. https://doi.org/10.1007/ s11746-003-0817-7 